\title{
Macrophages are Novel Sites of Expression and Regulation of Retinol Binding Protein-4 (RBP4)
}

\author{
M. BROCH ${ }^{1,5}$, R. RAMÍREZ ${ }^{3}$, M. T. AUGUET ${ }^{1,2,5}$, M. J. ALCAIDE ${ }^{3}$, C. AGUILAR ${ }^{1,5}$, \\ A. GARCIA-ESPAÑA ${ }^{4}$, C. RICHART ${ }^{1,2,5}$
}

${ }^{1}$ CIBER (CB06/03) Fisiopatologia de la Obesidad y Nutrición, Instituto de Salud Carlos III, Madrid, Spain, ${ }^{2}$ Internal Medicine Service, ${ }^{3}$ Surgery Service, ${ }^{4}$ Institut d'Investigació Sanitària Pere Virgili (IISPV), University Hospital of Tarragona Joan XXIII, Tarragona, Spain, ${ }^{5}$ Medicine and Surgery Department, Universitat Rovira i Virgili, Tarragona, Spain

Received November 13, 2008

Accepted March10, 2009

On-line June 19, 2009

\section{Summary}

Obesity is linked to a low-level chronic inflammatory state that may contribute to the development of associated metabolic complications. Retinol-binding protein 4 (RBP4) is an adipokine associated with parameters of obesity including insulin resistance indices, body mass index, waist circumference, lipid profile, and recently, with circulating inflammatory factors. Due to the infiltration of adipose tissue in obesity by macrophages derived from circulating monocytes and, on the other hand, the existence of a close genetic relationship between adipocytes and macrophages, we decided to examine if RBP4 is expressed in monocytes and/or primary human macrophages. While we did not detect expression of RBP4 in undifferentiated monocytes, RBP4 expression became evident during the differentiation of monocytes into macrophages and was highest in differentiated macrophages. Once we demonstrated the expression of RBP4 in macrophages, we checked if RBP4 expression could be regulated by inflammatory stimuli such as tumor necrosis factor-alpha (TNF- $\alpha$ ), interleukin-6 (IL-6), or the endotoxin lipopolysaccharide (LPS). We observed that while RBP4 expression was strongly inhibited by TNF-a and LPS, it was not affected by IL-6. Our results highlight the complexity behind the regulation of this adipokine and demonstrate that RBP4 expression in macrophages could be modulated by inflammatory stimuli.

\section{Key words}

RBP4 - Primary human macrophages - Inflammatory markers • Obesity

\section{Corresponding author}

M. Broch, Research Unit, University Hospital of Tarragona Joan XXIII, C/ Dr. Mallafré Guasch s/n, 43007 Tarragona, Spain. Fax: 34-977-29 58 33. E-mail: mbroch.hj23.ics@gencat.cat

Obesity induces an inflammatory state that is implicated in many of its metabolic complications, including insulin resistance, type 2 diabetes and atherosclerosis. The monocyte/macrophage system, which plays a prominent role in the onset of the atherosclerotic lesions, has recently been linked to obesity in humans, where circulating monocytes infiltrate adipose tissue (AT) and differentiate into macrophages (Weisberg et al. 2003). Monocytes could also be associated with global insulin resistance in a mice model in which the deletion of $\operatorname{Ik} \beta$ kinase (IKK- $\beta$ ), a central coordinator of inflammatory responses through activation of NF- $\kappa \beta$, in monocytes/macrophages cells hampers the development of systemic insulin resistance (Arkan et al. 2005).

Retinol binding protein-4 (RBP4) is an adipokine associated with obesity and a potential candidate to link glucose uptake in adipocytes to systemic 
insulin resistance (Yang et al. 2005). Moreover, elevated circulating RBP4 levels have also been recently associated with circulating inflammatory factors as $\mathrm{C}$ reactive protein (CRP) and IL-6 in obese children (Balagopal et al. 2007). Since adipocytes and macrophages seem genetically close, both cell types express similar sets of genes including numerous cytokines (Endemann et al. 1993, Makowski et al. 2001, Lee and Evans 2002), we decided to explore if RBP4 is also expressed in human monocytes/macrophages, and if so, whether it could be regulated by inflammatory stimuli.

Monocytes were isolated from peripheral blood mononuclears cells of healthy men ( $\mathrm{n}=6$, age: $39.4 \pm 4.8$ years, BMI: $30.8 \pm 3.8 \mathrm{~kg} / \mathrm{m}^{2}$ ) with the RosetteSep Human Monocyte Enrichment Cocktail Kit (StemCell Technologies, Vancouver, Canada) according to the manufacturer's instructions. Monocytes at a density of $3 \times 10^{6}$ cells/well, in $3 \mathrm{ml}$ of RPMI-1640 medium, were differentiated into macrophages with $10 \mathrm{ng} / \mathrm{ml}$ of granulocyte macrophage colony stimulating factor (GMCSF) (Sigma, St. Louis, MO, USA) for five days. Expression of CD68, a macrophage-specific gene used as a control of differentiation (Holmess and Simmons 1993), was strongly increased by day 5 compared to day 1 $\left(2.09 \pm 1.9 \times 10^{4}\right.$ vs. $\left.6.84 \pm 1.82 \times 10^{-1} ; \mathrm{p}=0.034\right)$. At day 5 of differentiation (Fig. 1A) the cell culture medium was replaced and macrophages were incubated with TNF- $\alpha$ $50 \mathrm{ng} / \mathrm{ml}$, IL-6 $50 \mathrm{ng} / \mathrm{ml}$, or endotoxin lipopolysaccharide (LPS) $1 \mu \mathrm{g} / \mathrm{ml}$ from Escherichia coli 026:B26 (Sigma) for $48 \mathrm{~h}$. As a positive control for adipokine production in monocytes/macrophages, we quantified mRNA expression and protein secretion of resistin (Patel et al. 2003). Total-RNA was isolated from cells with RNeasy ${ }^{\circledR}$ Mini Kit, (QIAGEN Science, Maryland, U.S.A). Reverse transcription was performed with one $\mu \mathrm{g}$ of total RNA with Reverse Transcription System Kit (Promega Corp., Madison, U.S.A.). Real-Time quantitative PCR for RBP4, Resistin, and CD68 was performed using Lightcycler technology with LightCycler ${ }^{\circledR}$ FastStart DNA master SYBR Green I Kit (Roche Diagnostics, Basel, Switzerland). To avoid the detection of non-specific PCR products, the purity of each amplified product was confirmed by agarose gel analysis and by melting curve analysis. RBP4 protein was measured in the cell culture medium using Human RBP4 ELISA Kit (AdipoGen, Seoul, Korea) with a limit detection of $1 \mathrm{ng} / \mathrm{ml}$ and a cross-reactivity with human RBP4 of $100 \%$, and without cross-reactivity with human resistin. Resistin was measured using Human Resistin ELISA Kit (BioVendor Laboratory Medicine, Inc., Czech Republic) with a limit detection of $0.2 \mathrm{ng} / \mathrm{ml}$. The statistical analysis was performed with the SPSS/PC+ (v.15 for Windows) and non-parametric tests for related samples. The level of significance was $\mathrm{p} \leq 0.05$. The Hospital's Ethics Committee approved the study and informed consent was obtained from each subject.

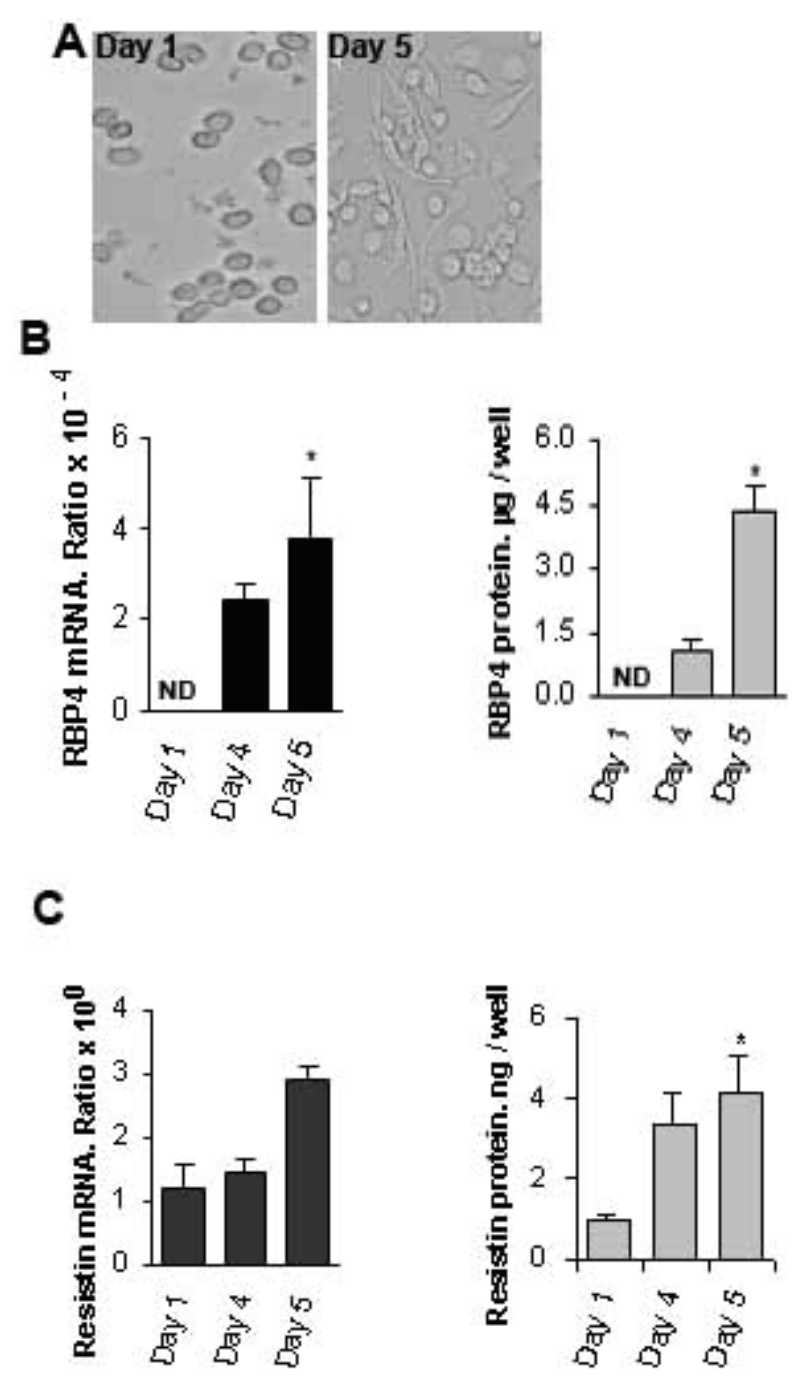

Fig. 1. RBP4 and resistin expression during differentiation of human circulating monocytes into macrophages. (A) Cell morphology at day 1 after plating and at day 5 of differentiation (X 400). (B) RBP4 and (C) resistin mRNA expression and protein secretion during differentiation. Ratio expresses mRNA gene/mRNA $\beta$-actin gene. Values are means \pm S.E.M. ND: not detected. * Indicates statistically significant difference $(p \leq 0.05)$ by Friedman $U$ test.

The expression of RBP4, at mRNA and protein levels, which was not detectable at the start of the differentiation process (monocytes), appeared at day 4 and was highest at day 5 (macrophages) (Fig. 1B). As we 
expected, the expression of resistin at mRNA and protein levels was evident in monocytes and was highest in macrophages (Fig. 1C). When macrophages (day 5) were incubated with inflammatory stimuli, RBP4 expression and protein levels were significantly downregulated by TNF- $\alpha$ and LPS, but remained unchanged in the incubation with IL-6 (Fig 2A). As expected, resistin was upregulated by all the stimuli, having the maximum effect with LPS (Fig. 2B) (Lehrke et al. 2007).
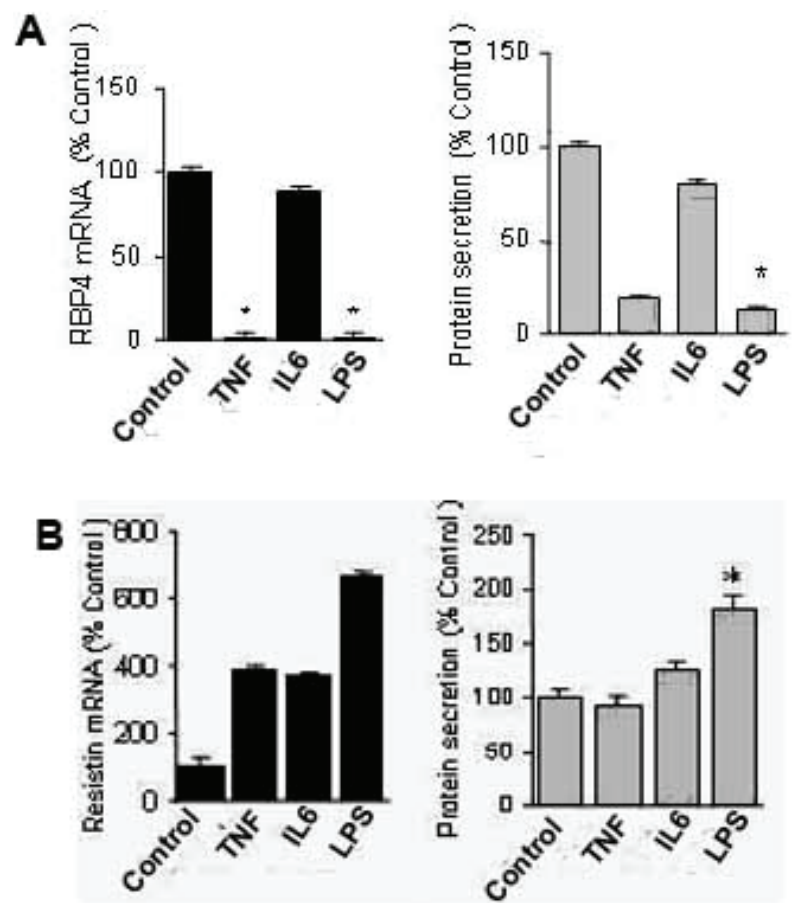

Fig. 2. (A) RBP4 and (B) resistin production in macrophages treated with TNF- $\alpha$, IL-6, and LPS. Results are expressed as the $\%$ of the values of untreated macrophages (control). * Indicates statistically significant difference compared with control $(p \leq 0.05)$ by Wilcoxon signed rank sum test.

In this communication we report for the first time the expression of RBP4 in human macrophages and its regulation by some inflammatory stimuli. This finding of RBP4 adipokine expression in human macrophages adds to the growing number of similarities between macrophages and adipocytes regarding the expression of cytokines and adipokines. What could be the clinical significance of the expression of RBP4 in macrophages? In general, due to various functions that macrophages perform in different tissues and in the formation of the atherosclerotic plaque during the onset of the atherosclerotic lesions (Linton and Fazio 2003), alterations in the expression and release of adipokines such as RBP4 by macrophages could be of biological importance. Thus, it has been suggested that the expression of resistin in monocytes-derived macrophages may contribute to the acceleration of atherogenesis, promoting lipid accumulation in human macrophages (Weibin et al. 2006). Since macrophages are a minor fraction of the cells in the adipose tissue, the effects of these alterations will probably be mediated through local signaling. In this sense, paracrine signaling by macrophages has been pointed out as the most likely mechanism behind the hampering in the development of systemic insulin resistance in mice (Arkan et al. 2005).

In particular, taking into consideration that in obesity the macrophages could account for 40-50\% of the total cells in adipose tissue (Weisberg et al. 2003) and a significant positive relationship between mRNA RBP4 expression in adipose tissue and macrophages infiltration has been found by Yao-Borengasser et al. (2007), local alterations in RBP4 release by macrophages in adipose tissue could have a significant biological effect in this tissue.

In addition, we found that the RBP4 expression in macrophages was regulated by inflammatory stimuli. The expression of resistin in macrophages was upregulated by all pro-inflammatory agents, in agreement with the increasing implication of this adipokine in inflammation and inflammation-related diseases (Shanshan and Yingying 2006). RBP4 expression was strongly downregulated by incubation of macrophages with TNF- $\alpha$ and LPS, whereas incubation with proinflammatory cytokine IL-6 had no effect (Fig. 2A). What could be the mechanism behind this differential regulation? Although TNF- $\alpha$ and LPS bind to different receptors in the cell surface, TNFR1/R2 and toll-like receptors (TLR), respectively, they trigger overlapping signal transduction pathways that activate similar transcription factors including activator protein-1 (AP-1) and nuclear factor $\mathrm{kB}$ (NF-kB) (Tesz et al. 2007). However, IL-6 activates different intracellular signaling pathways such as the Janus kinase (JAK) that activates transcription factors of the signal transducer and activator of transcription (STAT) pathways (Tesz et al. 2007). In agreement with our observation, TNF- $\alpha$ and LPS (but not IL-6) have been reported to be implicated in decreasing peroxisome proliferator-activated receptor gamma (PPAR $\gamma$ ) levels in adipocytes (Zhang et al. 1996, Mráček et al. 2004). Interestingly, PPAR $\gamma$ is a master regulator of adipogenesis and is induced during the differentiation of monocytes into macrophages at the same late stage at which we see the induction of RBP4 expression (Vosper 
et al. 2001). On the other hand, TNF- $\alpha$ downregulates RBP4 and PPAR $\gamma$ in adipocytes, where treatment with PPAR $\gamma$ ligand troglitazone increases both RBP4 and PPAR $\gamma$ (Sell and Eckel 2007). The above data together with our observation of downregulation of RBP4 by inflammatory stimuli and the high similarity in gene expression between adipocytes and macrophages could also indicate a positive link between RBP4 and PPAR $\gamma$ in macrophages.

Interestingly, similar to our results in macrophages, TNF- $\alpha$ strongly downregulates production of RBP4 in primary human adipocytes (Sell and Eckel 2007). On the other hand, in comparison with lean controls, lower levels of mRNA RBP4 expression in adipose tissue were found in obese women (Janke et al. 2006). These findings suggest that RBP4 expression in adipocytes and macrophages may be downregulated in states associated with elevated levels of pro-inflammatory mediators such as in obesity. The above observations appear to be contrary to the potential role that has been suggested for RBP4 as adipokine upregulated in obesity. However, the link between this adipokine and human obesity is not fully understood. Klöting et al. (2007) found that elevated systemic RBP4 levels correlated positively with adipose mRNA RBP4 and inversely with insulin sensitivity in obese subjects (Klöting et al. 2007). Moreover, subjects treated with agents that enhance insulin sensitivity have decreased systemic RBP4 levels (Hammarstedt et al. 2008, Lin et al. 2008). However,
RBP4 systemic levels do not always correlate with RBP4 expression in adipose tissue (Janke et al. 2006, YaoBorengasser et al. 2007). Furthermore, although it is generally accepted that TNF- $\alpha$ induces insulin resistance, it downregulates RBP4 expression in isolated adipocytes (Sell and Eckel 2007) and macrophages (Fig. 2A). In addition, agents that enhance insulin sensitivity, increased RBP4 expression in adipose tissue and in isolated adipocytes (Sell and Eckel 2007, Yao-Borengasser et al. 2007). It has been suggested that other tissues may contribute to systemic RBP4 levels in humans (YaoBorengasser et al. 2007), and probably other factors are implicated to alter the RBP4 production.

In summary, we reported for first time the appearance of RBP4 during differentiation of human monocytes into primary macrophages. This observation may have clinical significance due to the importance of tissue macrophages derived from circulating monocytes in inflammatory related pathologies such as atherosclerosis and obesity. Moreover, the regulation of this adipokine by TNF- $\alpha$ and LPS provides evidence that RBP4 may be involved in inflammatory responses. Our results highlights the complexity behind the regulation of this adipokine.

\section{Acknowledgements}

This work was supported by research grant SAF200500413 (to C.R) from the Ministerio de Educación y Ciencia of Spain and by the "Fundación Biociencia".

\section{References}

ARKAN MC, HEVENER AL, GRETEN FR, MAEDA S, LI Z, LONG JM, WYNSHAW-BORIS A, POLI G, OLEFSKY J: IKK- $\beta$ links inflammation to obesity-induced insulin resistance. Nat Med 11: 191-198, 2005.

BALAGOPAL P, GRAHAM TE, KAHN BB, ALTOMARE A, FUNANAGE V, GEORGE D: Reduction of elevated serum retinol binding protein (RBP4) in obese children by lifestyle intervention: association with subclinical inflammation. J Clin Endocrinol Metab 92: 1971-1974, 2007.

ENDEMANN G, STANTON LW, MADDEN KS, BRYANT CM, WHITE RT, PROTTER AA: CD36 is a receptor for oxidized low density lipoprotein. J Biol Chem 268: 11811-11816, 1993.

HAMMARSTEDT A, PIHLAJAMÄKI J, GRAHAM TE, KAINULAINEN S, KAHN BB, LAAKSO M, SMITH U: High circulating levels of RBP4 and mRNA levels of aP2, PGC-1 $\alpha$ and UCP-2 predict improvement in insulin sensitivity following pioglitazone treatment of drug-naive type diabetic subjects. J Intern Med 263: 440-449, 2008.

HOLMESS CL, SIMMONS DL: Molecular cloning of CD68, a human macrophage marker related to lysosomal glycoproteins. Blood 81: 1607-1613, 1993.

JANKE J, ENGELI S, BOSCHMANN M, ADAMS F, BÖHNKE J, LUFT FC, SHARMA AM, JORDAN J: Retinolbinding protein in human obesity. Diabetes 55: 2805-2810, 2006. 
KLÖTING N, GRAHAM TE, BERNDT J, KRALISCH S, KOVACS P, WASON CJ, FASSHAUER M, SCHÖN MR, STUMVOLL M, BLÜHER M, KAHN BB: Serum retinol-binding protein is more highly expressed in visceral than in subcutaneous adipose tissue and is a marker of intra-abdominal fat mass. Cell Metab 6: 79-87, 2007.

LEE CH, EVANS RM: Peroxisome proliferator-activated receptor- $\gamma$ in macrophage lipid homeostasis. Trends Endocrinol Metab 13: 331-335, 2002.

LEHRKE M, REILLY MP, MILLINGTON SC, IQBAL N, RADER DJ, LAZAR MA: An inflammatory cascade leading to hyperresistinemia in humans. PLoS Med 1: 191-197, 2007.

LIN KD, CHANG YH, WANG CL, YANG YH, HSIAO PJ, LI TH, SHIN SJ: Thiazolidinedione addition reduces the serum retinol-binding protein 4 in type 2 diabetic patients treated with metformin and sulfonylurea. Transl Res 151: 309-314, 2008.

LINTON MF, FAZIO S: Macrophages, inflammation, and atherosclerosis. Int J Obes Relat Metab Disord 27: S35-S40, 2003.

MAKOWSKI L, BOORD JB, MAEDA K, BABAEV VR, UYSAL KT, MORGAN MA, PARKER RA, SUTTLES J, FAZIOS S, HOTAMISLIGIL GS, LINTON MF: Lack of macrophage fatty-acid binding protein aP2 protects mice deficient in apolipoprotein E against atherosclerosis. Nat Med 7: 699-705, 2001.

MRÁČEK T, CANNON B, HOUŠTĚK J: IL-1 and LPS but not IL-6 inhibit differentiation and downregulate PPAR $\gamma$ in brown adipocytes. Cytokine 26: 9-15, 2004.

PATEL L, BUCKELS AC, KINGHORN IJ, MURDOCK PR, HOLBROOK JD, PLUMPTON CH, MACPHEE CH, SMITH SA: Resistin is expressed in human macrophages and directly regulated by PPAR $\gamma$ activators. Biochem Biophys Res Commun 300: 472-476, 2003.

SELL H, ECKEL J: Regulation of retinol binding protein 4 production in primary human adipocytes by adiponectin, troglitazone and TNF- $\alpha$. Diabetologia 50: 2221-2223, 2007.

SHANSHAN P, YINGYING L: Role of resistin in inflammation and inflammation-related diseases. Cell Mol Immunol 3: 29-34, 2006.

TESZ GJ, GUILHERME A, GUNTUR KV, HUBBARD AC, TANG X, CHAWLA A, CZECH MP: Tumor necrosis factor $\alpha(\mathrm{TNF} \alpha)$ stimulates Map4k4 expression through TNF $\alpha$ receptor 1 signaling to c-Jun and activating transcription factor 2. J Biol Chem 282: 19302-19312, 2007.

VOSPER H, PATEL L, GRAHAM TL, KHOUDOLI GA, HILL A, MACPHEE CH, PINTO I, SMITH SA, SUCKLING KE, WOLF CR, PALMER CNA: The peroxisome proliferator-activated receptor $\gamma$ promotes lipid accumulation in human macrophages. J Biol Chem 23: 44258-44265, 2001.

WEIBIN X, LU Y, WENZHONG Z, MIN L: Resistin increases lipid accumulation and CD36 expression in human macrophages. Biochem Biophys Res Commun 351: 376-382, 2006.

WEISBERG SP, MCCANN D, DESAI M, ROSENBAUM M, LEIBLE RL, FERRANTE JR AW: Obesity is associated with macrophage accumulation in adipose tissue. J Clin Invest 112: 1796-1808, 2003.

YANG Q, GRAHAM TE, MODY N, PREITNER F, PERONI OD, ZABOLOTNY JM, KOTANI K, QUADROL L, KAHN BB: Serum retinol binding protein 4 contributes to insulin resistance in obesity and type 2 diabetes. Nature 436: 356-362, 2005.

YAO-BORENGASSER A, VARMA V, BODLES AM, RASOULI N, PHANAVANH B, LEE MJ, STARKS T, KERN LM, SPENCER HJ, RASHIDI AA, MCGEHEE RE, FRIED SK, KERN PA: Retinol binding protein 4 expression in humans. Relationship to insulin resistance, inflammation, and response to pioglitazone. $J C l i n$ Endocrinol Metab 92: 2590-2597, 2007.

ZHANG B, BERGER J, HU E, SZALKOWSKI D, WHITE-CARRINGTON S, SPIEGELMAN BM, MOLLER DE: Negative regulation of peroxisome proliferator-activated receptor-gamma gene expression contributes to the antiadipogenic effects of tumor necrosis factor-alpha. Mol Endocrinol 10: 1457-1466, 1996. 